\title{
Serum levels of $3 \alpha$-androstanediol glucuronide in hirsute and non hirsute women
}

\author{
L Falsetti, B Rosina and D De Fusco \\ Department of Gynaecological Endocrinology, University of Brescia, Italy \\ (Correspondence should be addressed to L Falsetti, Via Tirandi, 13-scala F, 25128 Brescia, Italy)
}

\begin{abstract}
This study has evaluated the behaviour of $3 \alpha$-androstanediol glucuronide ( $3 \alpha$-diol G) in 170 women of whom 85 had polycystic ovary syndrome (PCOS), 35 had idiopathic hirsutism (IH) and 50 had regular cycles (control group). Of the women with PCOS, 45 were hirsute (PCOS-H) and 40 were non hirsute (PCOS-NH). Women in the control group were not hirsute. Hirsutism was assessed by the same physician using the Ferriman-Gallway score. The body mass index (BMI) was estimated in all of the women.

Plasma concentrations of $3 \alpha$-diol G were elevated only in hirsute patients, both with PCOS and with $\mathrm{IH}$. Even in PCOS-NH, concentrations of $3 \alpha$-diol G were higher compared with controls $(P<0.001)$, but significantly lower $(P<0.001)$ than those of the PCOS-H and of the IH groups. The behaviour of $3 \alpha-$ diol $\mathrm{G}$ was not affected by BMI.
\end{abstract}

European Journal of Endocrinology 138 421-424

\section{Introduction}

Hirsutism, affecting $5-8 \%$ of the whole female population of fertile age, is an important clinical and psychological problem. Hirsutism is associated with an increased production or action of androgens. Hyperandrogenism was found in $60-80 \%$ of hirsute women, while in 10-15\% circulating levels of androgens and of $17 \alpha$-hydroxyprogesterone (17OHP) were normal even after the adrenocorticotrophin (ACTH) stimulation test (idiopatic hirsutism) $(1,2)$. Sixty-five to eighty-five percent of women with androgen excess had polycystic ovary syndrome (PCOS) or hyperthecosis (3-5). Despite hyperandrogenism, about $30 \%$ of women with PCOS did not present with hirsutism (6).

Several studies have shown that in all hirsute women, both with PCOS and idiopatic hirsutism (IH), the activity of $5 \alpha$-reductase in the genital skin was steadily elevated $(7-10)$.

$3 \alpha$-Androstanediol glucuronide ( $3 \alpha$-diol G) is considered to be an excellent marker of peripheral androgen action and especially of $5 \alpha$-reductase activity $(11,12)$. It has been shown that the skin can form C-19 conjugates directly (13). A primary alteration in $5 \alpha$ reductase and in the androgen metabolism of the skin could be the cause of hirsutism in many cases.

The clinical use of $3 \alpha$-diol G as a marker of peripheral androgen action is, however, controversial because many authors deduce that the origin of $3 \alpha$-diol G, and therefore its plasma concentrations, reflect adrenal androgen production and hepatic metabolism $(14,15)$.
The aim of our study is to provide further contributions to the clinical activity of $3 \alpha$-diol $\mathrm{G}$ by evaluating its behaviour in a broad series of normal and hyperandrogenic women, with and without hirsutism.

\section{Materials and methods}

\section{Subjects}

Since 1994 plasma assays of $3 \alpha$-diol $G$ have been carried out in 170 women aged 17 to 35 years. The patients were divided into the following groups: 50 normal females (control group), aged 18 to 35 years, body mass index (BMI) $21.6 \pm 2.5 \mathrm{~kg} / \mathrm{m}^{2}$; 85 women with PCOS, aged 17 to 29 years, BMI $24.3 \pm 4.6 \mathrm{~kg} / \mathrm{m}^{2}$, of whom 45 were hirsute (PCOS-H) and 40 non hirsute (PCOS-NH); 35 women with $\mathrm{IH}$, aged 17 to 25 years, BMI $22.5 \pm 5 \mathrm{~kg} / \mathrm{m}^{2}$. All subjects were healthy and had taken no medication during the previous three months. We excluded patients with Cushing's syndrome, late onset congenital adrenal hyperplasia, prolactin secreting pituitary adenomas, and androgen secreting ovarian or adrenal neoplasia. The controls had regular ovulatory cycles (luteal phase serum progesterone levels $>4 \mathrm{ng} / \mathrm{ml}$ ) and no clinical evidence of hyperandrogenism. The diagnosis of PCOS was made according to the clinical (various cycle alterations, acne and hirsutism) and endocrine (chronic anovulation, elevated serum luteinizing hormone (LH), 170HP and androgen levels, mean LH/follicle-stimulating hormone 
(FSH) ratio $>2$ ) data. Insulin resistance was present in $49(57.6 \%)$ of 85 women with PCOS, of whom $27(60 \%)$ were PCOS-H and 22 (55\%) were PCOS-NH. The insulin resistance was measured by the oral glucose tolerance test (OGTT). A normal insulinaemic response to OGTT was considered as a maximum insulinaemic level of $100 \mu \mathrm{U} / \mathrm{ml}$, as estabilished by standard procedures in our laboratory, while a normal glycaemic response to OGTT was defined according to the criteria of the National Diabetes Data Group (16).

IH women had normal menstrual cycles and plasma levels of androgens and 170HP, both in basal conditions and after the ACTH stimulation test. The ACTH test (administration of a single i.v. bolus of $0.25 \mathrm{mg}$ synthetic ACTH (Synacten), Ciba-Geigy, Varese, Italy) was performed in women with $\mathrm{IH}$ when early follicular phase serum $17 \mathrm{OHP}$ levels were $\geq 30 \mathrm{nmol} / \mathrm{l}$. Hirsutism was evaluated by the Ferriman-Gallway score (17) and only patients with a score $\geq 8$ were considered hirsute. Women with BMI $>25 \mathrm{~kg} / \mathrm{m}^{2}$ were considered overweight/obese.

\section{Hormone assays}

Plasma assays of $3 \alpha$-diol G were carried out between 0800 and $0900 \mathrm{~h}$ for two consecutive days in all women in the follicular phase (days 4 to 7 ) of a spontaneous or induced cycle. The value of $3 \alpha$-diol $\mathrm{G}$ in each subject expressed the average of two determinations. In 85 patients with PCOS and oligo-amenorrhoea the cycle was induced with the administration of medroxyprogesterone acetate at a dose of $10 \mathrm{mg}$ daily for five consecutive days. Progesterone and C-19 derivate progestins but not medroxyprogesterone acetate, reduce in vitro $5 \alpha$-reductase activity in female genital skin (18). The effects of medroxyprogesterone acetate (at the highest dose) in hyperandrogenic patients with PCOS are probably related to inibition of androgen through suppression of LH and an increase in the hepatic clearance of testosterone. Serum $3 \alpha$-diol G levels were assayed by means of the RIA method (kit from Diagnostic Systems Laboratories, Webster, TX, USA). Serum LH, FSH and sex hormone binding globulin (SHBG) levels were assayed using immunoradiometric assay methods (kits by Radim, Rome, Italy). Other hormones were assayed using radioimmunoassay commercial kits from Diagnostic Products Corporation, Los Angeles, CA, USA (17OHP, testosterone, free testosterone) and Medgenix, Brussels, Belgium (fasting insulin). Glycaemia was assayed with the herokinase UV test (Boehringer-Mannheim test-Combination, Boehringer-Mannheim, Mannheim, Germany). Conversion factors to SI units were: $3 \alpha$-diol G, 2.136; total and free testosterone, 3.467; insulin, 7.175.

The study was carried out with the patients' consent and approved by the Ethical Committee of the University of Brescia.

\section{Statistical methods}

All data, normally distributed in each group, are expressed as means \pm S.D. Analysis of variance (ANOVA) was used to evaluate differences between $3 \alpha$-diol G concentrations among the different groups. A $P$ value $<0.05$ was considered statistically significant.

\section{Results}

The values for $3 \alpha$-diol $\mathrm{G}$ in all groups of patients are summarized in Table 1. Plasma levels of $3 \alpha$-diol G in all the women with PCOS $(n=85)$ were $4.8 \pm 1.4 \mathrm{ng} / \mathrm{ml}$, in women with $\mathrm{IH}(n=35)$ they were $5.8 \pm 1.1 \mathrm{ng} / \mathrm{ml}$ and in the controls $(n=50)$ they were $1.5 \pm 0.5 \mathrm{ng} / \mathrm{ml}$.

When the PCOS group was subdivided according to hirsutism, $45(53 \%)$ of the patients were hirsute (Ferriman-Gallway score $12.2 \pm 2.7$ ) and $40(47 \%)$ were non hirsute. The age of the PCOS-H patients was between 18 and 29 years with a BMI of $24.7 \pm$ $4.7 \mathrm{~kg} / \mathrm{m}^{2}$, and the age of the PCOS-NH patients was between 17 and 27 years with a BMI of $23.8 \pm$ $4.6 \mathrm{~kg} / \mathrm{m}^{2}$. The incidence of changes in the menstrual cycle (oligomenorrhoea, amenorrhoea) was not different in the two subgroups (PCOS-H: oligomenorrhoea $67 \%$, secondary amenorrhoea 33\%; PCOS-NH: oligomenorrhoea $67.5 \%$, secondary amenorrhoea $32.5 \%$ ). Obesity was also equally distributed in the two subgroups: 18 (40\%) PCOS-H patients (BMI: $29.5 \pm$ $3.2 \mathrm{~kg} / \mathrm{m}^{2}$ ) and $14(35 \%)$ PCOS-NH patients (BMI: $27.5 \pm 1 \mathrm{~kg} / \mathrm{m}^{2}$ ).

The endocrine profile for PCOS-H did not differ significantly from that for PCOS-NH in total testosterone $(1.2 \pm 0.4 \mathrm{ng} / \mathrm{ml}$ vs $1.1 \pm 0.3 \mathrm{ng} / \mathrm{ml})$, free testosterone $(3.6 \pm 0.9 \mathrm{pg} / \mathrm{ml}$ vs $3.3 \pm 0.8 \mathrm{pg} / \mathrm{ml})$ and SHBG $(22.0 \pm$ $8.0 \mathrm{nmol} / \mathrm{l}$ vs $24.2 \pm 7.5 \mathrm{nmol} / \mathrm{l})$, but it differed significantly in fasting insulin $(11.7 \pm 3.5 \mu \mathrm{U} / \mathrm{ml}$ vs $9.3 \pm 3 \mu \mathrm{U} / \mathrm{ml}) \quad(P<0.01)$ and $3 \alpha$-diol $\mathrm{G}$ levels $(6.1 \pm 1.7 \mathrm{ng} / \mathrm{ml}$ vs $3.5 \pm 1.0 \mathrm{ng} / \mathrm{ml})(P<0.001)$. In the 35 women with IH (Ferriman-Gallway score $12 \pm 2.3)$, obesity was present in 5 cases $(14.3 \%)$ (BMI: $28.4 \pm 5 \mathrm{~kg} / \mathrm{m}^{2}$ ) and hormone values were similar to the control group for total testosterone $(0.5 \pm 0.1 \mathrm{ng} / \mathrm{ml}$ vs $0.4 \pm 0.2 \mathrm{ng} / \mathrm{ml})$, free testosterone

Table 1 Serum $3 \alpha$-diol G concentrations in PCOS- $\mathrm{H}$, $\mathrm{PCOS}-\mathrm{NH}, \mathrm{IH}$ and control groups. Values are means \pm S.D.

\begin{tabular}{lcc}
\hline & $\boldsymbol{n}$ & 3 $\boldsymbol{\alpha}$-diol $\mathbf{G}(\mathrm{ng} / \mathrm{ml})$ \\
\hline PCOS-H & 45 & $6.1 \pm 1.7^{*}$ \\
PCOS-NH & 40 & $3.5 \pm 1.0^{*} \dagger$ \\
$\mathrm{IH}$ & 35 & $5.8 \pm 1.1^{*}$ \\
Control & 50 & $1.5 \pm 0.5^{*} \dagger$ \\
\hline${ }^{*} P<0.001$ & PCOS-H and IH vs & PCOS-NH and \\
control. & & \\
$\dagger P<0.001$ & PCOS-NH vs control.
\end{tabular}


Table 2 Serum $3 \alpha$-diol G concentrations in the PCOS-H, PCOS-NH and IH patients subdivided by weight into obese and normal weight patients. Values are means \pm S.D.

\begin{tabular}{|c|c|c|c|c|c|c|}
\hline & \multicolumn{2}{|c|}{ PCOS-H } & \multicolumn{2}{|c|}{ PCOS-NH } & \multicolumn{2}{|c|}{ IH } \\
\hline & Obese & Normal & Obese & Normal & Obese & Normal \\
\hline Number of patients & 18 & 27 & 14 & 26 & 5 & 30 \\
\hline $\operatorname{BMI}\left(\mathrm{kg} / \mathrm{m}^{2}\right)$ & $29 \pm 3.2$ & $21 \pm 2.8$ & $27.5 \pm 1.0$ & $21 \pm 1.4$ & $28.4 \pm 5.0$ & $21.2 \pm 1.8$ \\
\hline $3 \alpha$-diol G (ng/ml) & $5.9 \pm 1.5$ & $6 \pm 1.7$ & $3.5 \pm 0.9$ & $3.4 \pm 1.2$ & $5.6 \pm 0.8$ & $5.8 \pm 1.2$ \\
\hline
\end{tabular}

$(2 \pm 0.6 \mathrm{pg} / \mathrm{ml}$ vs $1.8 \pm 0.6 \mathrm{pg} / \mathrm{ml})$, SHBG $(45.3 \pm$ $6.1 \mathrm{nmol} / \mathrm{l}$ vs $47 \pm 9.6 \mathrm{nmol} / \mathrm{l})$ and fasting insulin $(5 \pm 1.9 \mu \mathrm{U} / \mathrm{ml}$ vs $5.1 \pm 1.1 \mu \mathrm{U} / \mathrm{ml})$. The levels of $3 \alpha-$ diol $\mathrm{G}$ in the women with IH were significantly greater than in the control group $(5.8 \pm 1.1 \mathrm{ng} / \mathrm{ml}$ vs $1.5 \pm$ $0.5 \mathrm{ng} / \mathrm{ml})(P<0.001)$.

Statistical analysis (Table 1) showed that serum $3 \alpha$ diol G levels in hirsute women, both with PCOS and IH, were significantly higher $(P<0.001)$ than those of PCOS-NH and controls. The serum $3 \alpha$-diol G levels in PCOS-H were not different from those in $\mathrm{IH}$ while there were significant differences $(P<0.001)$ between PCOS-NH and controls.

Table 2 shows the values for $3 \alpha$-diol G in PCOS-H, PCOS-NH and IH groups when each is divided into obese or normal weight patients according to their BMIs. In each group of patients, no significant variations in plasma levels of $3 \alpha$-diol $\mathrm{G}$ were observed between obese and normal weight women.

\section{Discussion}

Our results have shown that higher levels of $3 \alpha$-diol G are found only in hirsute patients, and are independent of androgen levels (hyperandrogenic subjects $n=45$, normal androgenic subjects $n=35$ ) and of BMI. Even values for $3 \alpha$-diol G in PCOS-NH were higher compared with the controls although significantly lower than those in hirsute women.

Therefore, in women, different plasma concentrations of $3 \alpha$-diol G can be established, ranging from normal $(1.5 \pm 0.5 \mathrm{ng} / \mathrm{ml})$ to intermediate $(3.5 \pm 1.0 \mathrm{ng} / \mathrm{ml})$ or very elevated values $(\geq 5.8 \pm 1.1 \mathrm{ng} / \mathrm{ml})$. The different quantities of $3 \alpha$-diol $\mathrm{G}$ probably express various degrees of $5 \alpha$-reductase activity (or possibly different types of $5 \alpha$-reductase) and different concentrations of dihydrotestosterone (DHT) in the pilosebaceous unit.

It is known that the activity of $5 \alpha$-reductase can be stimulated not only by circulating levels of androgens, but also by genetic factors (19), insulin and the insulinlike growth factor-I/insulin-like growth factor-binding protein (IGF-I/IGFBP) system (20).

Many studies have proved that in PCOS and in IH there is an increased $5 \alpha$-reductase activity in the genital skin and that plasma levels of $3 \alpha$-diol $\mathrm{G}$ are correlated to the activity of $5 \alpha$-reductase and to the production of DHT (21-23).
In the literature and in our series, 30\% (20) and 47\% of women with PCOS did not have hirsutism. Therefore, the concentrations of $3 \alpha$-diol G $(3.5 \pm 1.0 \mathrm{ng} / \mathrm{ml})$ found in the PCOS-NH group expressed an increase in $5 \alpha$ reductase and in DHT which was not sufficient to induce hirsutism. In PCOS, the increase in androgens and in the insulin/IGF-I/IGFBP system probably contributes to the increase in $5 \alpha$-reductase activity and the production of DHT, but is not the main cause of hirsutism.

Hirsutism only appears when plasma levels of $3 \alpha$-diol $\mathrm{G}$ are very elevated, giving evidence of maximum $5 \alpha$ reductase activity and of an elevated formation of DHT in the hair follicle.

The levels of $3 \alpha$-diol G in IH and in PCOS-H, compared with PCOS-NH, suggests the importance of genetic factors in the regulation of $5 \alpha$-reductase and the key role of peripheral events in the determination of hirsutism.

The correlation between $3 \alpha$-diol G and hirsutism, and the values of $3 \alpha$-diol $\mathrm{G}$ in controls and in PCOS-NH, suggests a cutaneous origin of $3 \alpha$-diol G. Our results, obtained from a broad series, confirm the clinical usefulness of $3 \alpha$-diol $\mathrm{G}$ as a marker of the peripheral metabolism of androgens. The $3 \alpha$-diol G dosage can be employed to monitor various therapies for hirsutism.

\section{References}

1 Knocherhauer ES \& Azziz R. Advances in the diagnosis and treatment of the hirsute patients. Current Opinion in Obstetrics and Gynecology 19957 344-350.

2 Barbieri RL. Hyperandrogenic disorders. Clinical Obstetrics and Gynecology 199033 640-654.

3 Maroulis GB. Evaluation of hirsutism and hyperandrogenemia. Fertility and Sterility 1981 273-305.

4 Rittmaster RS \& Loriaux DL. Hirsutism. Annals of Internal Medicine 1987106 95-99.

5 Hatch R, Rosenfield RL, Kim MH \& Tredway D. Hirsutism: implications and etiology and management. American Journal of Obstetrics and Gynecology 1981140 815-830.

6 Goldzieher JW \& Axelrod IR. Clinical and biochemical features of polycystic ovarian disease. Fertility and Sterility 196314 631653.

7 Stewart PM, Shackleton CHL, Beastall GH \& Edwards CRW. $5 \alpha-$ Reductase activity in polycystic ovary syndrome. Lancet 1990 $335431-433$.

8 Lobo RA, Goebelrmann U \& Horton R. Evidence for the importance of peripheral tissue events in the development of hirsutism in polycystic ovary syndrome. Journal of Clinical Endocrinology and Metabolism 198357 393-397. 
9 Serafini PC \& Lobo RA. Increased 5 alpha-reductase activity in idiopathic hirsutism. Fertility and Sterility 198543 74-78.

10 Kutten F, Mowszowicz I, Schaison G \& Mauvais-Jarvis P. Androgen production and skin metabolism in hirsutism. Journal of Endocrinology 197775 83-89.

11 Horton R, Hawks D \& Lobo R. 3 alpha- and 17 betaandrostanediol glucuronide in plasma: a marker of androgen action in idiopathic hirsutism. Journal of Clinical Investigation 198262 1203-1206.

12 Carmina E, Stanczyk FZ, Gentzchein E \& Lobo R. Time-dependent changes in serum $3 \alpha$-androstanediol glucuronide correlate with hirsutism scores after ovarian suppression. Gynecological Endocrinology 19959 215-220.

13 Horton R \& Lobo R. Peripheral androgens and the role of androstanediol glucuronide. Journal of Clinical Endocrinology and Metabolism 198615 293-306.

14 Giagulli VA, Verdnock L, Deslypere JP, Giorgino R \& Vermeulen A. Comparison of plasma androgen glucuronide levels after percutaneous or peroral androgen treatment in men: evidence for important splanchnic contribution to plasma 17 beta-hydroxyandrogen glucuronides. Journal of Clinical Endocrinology and Metabolism 199376 429-431.

15 Rittmaster RS. Androgen conjugates: physiology and clinical significance. Endocrine Reviews 199314 121-132.

16 National Diabetes Data Group. Classification and diagnosis of diabetes mellitus and other categories of glucose intolerance. Diabetes 197928 1039-1057.
17 Ferriman D \& Gallway JD. Clinical assessment of body hair growth in women. Journal of Clinical Endocrinology and Metabolism 1961 21 1440-1448.

18 Cassidenti DL, Paulson RJ, Serafini P, Stanczyk FZ \& Lobo AR. Effects of sex steroids on skin $5 \alpha$-reductase activity in vitro. Obstetrics and Gynaecology 199178 103-107.

19 Jahanfar S, Eden JA, Warren P, Seppala M \& Nguyen TV. A twin study of polycystic ovary syndrome. Fertility and Sterility 199563 478-486.

20 Lobo RA. Hirsutism in polycystic ovary syndrome: current concepts. Clinical Obstetrics and Gynecology 199134 817-826.

21 Paulson RJ, Serafini PC, Catalino JA \& Lobo RA. Measurements of 3 alpha, 17 beta-androstanediol glucuronide in serum and urine and the correlation with the skin 5 alpha-reductase activity. Fertility and Sterility $198646222-226$.

22 Lobo RA, Paul WL, Gentzschein E, Serafini PC, Catalino JA \& Paulson RJ. Production of 3 alpha-androstanediol glucuronide in human genital skin. Journal of Clinical Endocrinology and Metabolism 198765 711-714.

23 Duffy DM, Legro RS, Chang L, Stanczyk FZ \& Lobo R. Metabolism of dihydrotestosterone to 5 alpha-androstane- 3 alpha, 17 beta-diol glucuronide is greater in the peripheral compartment than in the splanchnic compartment. Fertility and Sterility $199564736-739$.

Received 30 May 1997

Accepted 5 January 1998 